\title{
Fabrication of all-ceramic crowns by a new method
}

\author{
Takayuki MASUDA, Kazutoshi KAKIMOTO, Kazuya TAKAHASHI and Yutaka KOMASA \\ Department of Geriatric Dentistry, Osaka Dental University, 8-1 Kuzaha-Hanazonochou Hirakatashi, Osaka 573-1121, Japan \\ Corresponding author, Takayuki MASUDA; E-mail: masuda-t@cc.osaka-dent.ac.jp
}

\begin{abstract}
A new method of all-ceramic production using alumina coping has been developed. The present study investigates the influence of secondary firing (glass infiltration firing) conditions. Samples of porcelain build-up without secondary firing were also assessed. The suitability of coping that included secondary firing was found to be affected by the rate of temperature increase during the secondary firing. However, cracking developed in the fired porcelain if porcelain was built up onto secondarily-fired coping. In contrast, cracking did not occur with coping that was not secondarily fired. The bending strength after porcelain build-up was $70 \mathrm{MPa}$ or higher, suggesting the possibility of clinical applications as an anterior crown. These findings establish that this is method of producing allceramic crowns that allows for low-cost manufacture in a short period of about $1 \mathrm{~h}$.
\end{abstract}

Keywords: All-ceramic crown, Coping, New methods, Porcelain build-up

\section{INTRODUCTION}

Zirconia is currently the most commonly used material in all-ceramic crowns. However, zirconia is harder than enamel, thus having the potential to cause attrition or fracturing of the antagonist ${ }^{1)}$. For that reason, it is necessary to polish well before setting it ${ }^{2}$. The production of an all-ceramic crown using zirconia requires expensive equipment and numerous procedures, such as 3D scanning of the model, computer-assisted design (CAD), machining via $\mathrm{CAD}$ and computer-aided manufacturing (CAD/CAM), coping firing, and porcelain build-up and firing. Conventional alumina coping methods also necessitate expensive equipment and time-consuming procedures.

Therefore, we have developed a new all-ceramic crown production technique that uses alumina coping but does not require special equipment. Further, this technique can be performed within a short period of time. Previous research has succeeded in reducing the coping production time to $14 \mathrm{~min}$, however, the coping fit was found to be reduced after the primary firing stage. Attempts have therefore been made to improve this characteristic through slip drying methods. The results indicated an improvement in the coping fit after primary firing, but a decrease in this characteristic following secondary firing.

In the present study, we conducted four tests aimed at investigating the strength and improvement in coping and crown fits after porcelain build-up and firing, and to establish a new production method. Test 1 examined the fit performance dependence on the heating rate during secondary firing. Test 2 examined porcelain build-up on copings produced via primary and secondary firing, and determined the conditions of the resultant crowns after firing. Test 3 examined the fits of the samples produced in test 2 , while test 4 examined the three-point bending strength of the samples produced using the same method, in order to confirm their strength.

\section{MATERIALS AND METHODS}

\section{Materials}

The materials used in the coping production were as follows. The mixing powder was obtained by mixing alumina powder with a mean grain size of $58 \mu \mathrm{m}$ (A-12, Showa Denko, Tokyo, Japan), alumina powder with a mean grain size of $8.5 \mu \mathrm{m}$ (AS-40, Showa Denko), and lithium silicate glass with a mean grain size of $20 \mu \mathrm{m}$ (Frit M, Iwatsuki Kako, Toyonaka, Japan) at a ratio of 40:50:10 wt $\%^{3,4)}$. A mixing solution, which was composed of $47 \%$ ammonium silicate solution (AS-17, Nippon Chemical, Tokyo, Japan) was also used. "Sprinkle powder," containing alumina powder with a mean grain size of $58 \mu \mathrm{m}$ (A-12, Showa Denko) was obtained, along with a wax separation material (SureSep, GC, Tokyo, Japan) and infiltration glass, which was comprised of glass powder (In-Ceram ${ }^{\circledR}$ Alumina Glass Powder, VITA Hakusui Trading, Osaka, Japan).

The process used to produce the alumina coping examined in the present study was as follows ${ }^{3-6)}$ :

1) A working model was coated with the abovedescribed separation material.

2) The working model was then coated with a turbid alumina solution comprised of a mixture of the mixing powder and mixing solution.

3) The sprinkle powder was quickly scattered on the model surface until the surface was dry.

4) The coping was dried.

5) Steps 2-4 were repeated three or four times so as to increase the coping thickness.

6) The coping was covered with sticky wax to prevent damage when it was removed from the working model.

7) The coping was placed in an electric furnace at $900^{\circ} \mathrm{C}$ for $1 \mathrm{~h}$ (Auto-Furnace QM-1, GC). It was then removed from the electric furnace and cooled to room temperature. This was the primary firing of the coping. 
8) The infiltration glass was placed on the coping surface, which was then heated to $1,100^{\circ} \mathrm{C}$ in an electric furnace (SuperTherm Rapid Thermal Annealing Furnace PRO-X, Chugai PRO-X, Tokyo, Japan) and maintained at this temperature for $2 \mathrm{~h}$, before being rapidly cooled to room temperature. This was the secondary firing (glass infiltration firing).

9) The excess glass on the surface was milled using a diamond point as a finishing process.

10) Porcelain was applied to the coping and fired, yielding a final thickness of approximately 2 $\mathrm{mm}$.

\section{Methods}

The methods used in tests $1-4$ of the present study are described below.

Test 1 examined the dependence of the coping fit on the rate of temperature increase during secondary firing (glass infiltration firing). Note that previous studies have not specifically defined a heating rate, with the secondary firing being performed at the most rapid temperature increase conditions provided by whichever electric furnace was used (in this case, a SuperTherm
Rapid Thermal Annealing Furnace PRO-X, Chugai PRO-X). Therefore, we investigated the coping fit dependence on the heating rate during the secondary firing process. The following rates were employed: 1) No setting $\left(1,100^{\circ} \mathrm{C}\right.$ was attained in $\left.19 \mathrm{~min}\right)$; 2) $10^{\circ} \mathrm{C} / \mathrm{min}$; 3) $30^{\circ} \mathrm{C} / \mathrm{min}$; and 4) $50^{\circ} \mathrm{C} / \mathrm{min}$. After $2 \mathrm{~h}$ in the furnace at $1,100^{\circ} \mathrm{C}$ under all of these conditions, the samples were removed from the furnace and rapidly cooled to room temperature. Any changes in the coping suitability after both the primary and secondary firings were then examined.

Figure 1 shows the model used in the test, which modeled the morphology of a molar abutment tooth. The mold had a diameter of $10 \mathrm{~mm}$ and height of $5 \mathrm{~mm}$ at the cervical margin, and the occlusal surface had a round morphology with a radius of curvature of $0.8 \mathrm{~mm}$. Part of the occlusal surface was given an inclined surface with a height of $1 \mathrm{~mm}$ and incline of $45^{\circ}$, in order to enable accurate repositioning of the coping on the die. The marginal morphology was a rounded shoulder, and the axial surface taper angle was $6^{\circ 3-7)}$.The working model was fabricated using super-hard gypsum (New Fujirock IMP, GC) after an impression of the mold was taken using a silicone impression material for multiple molds
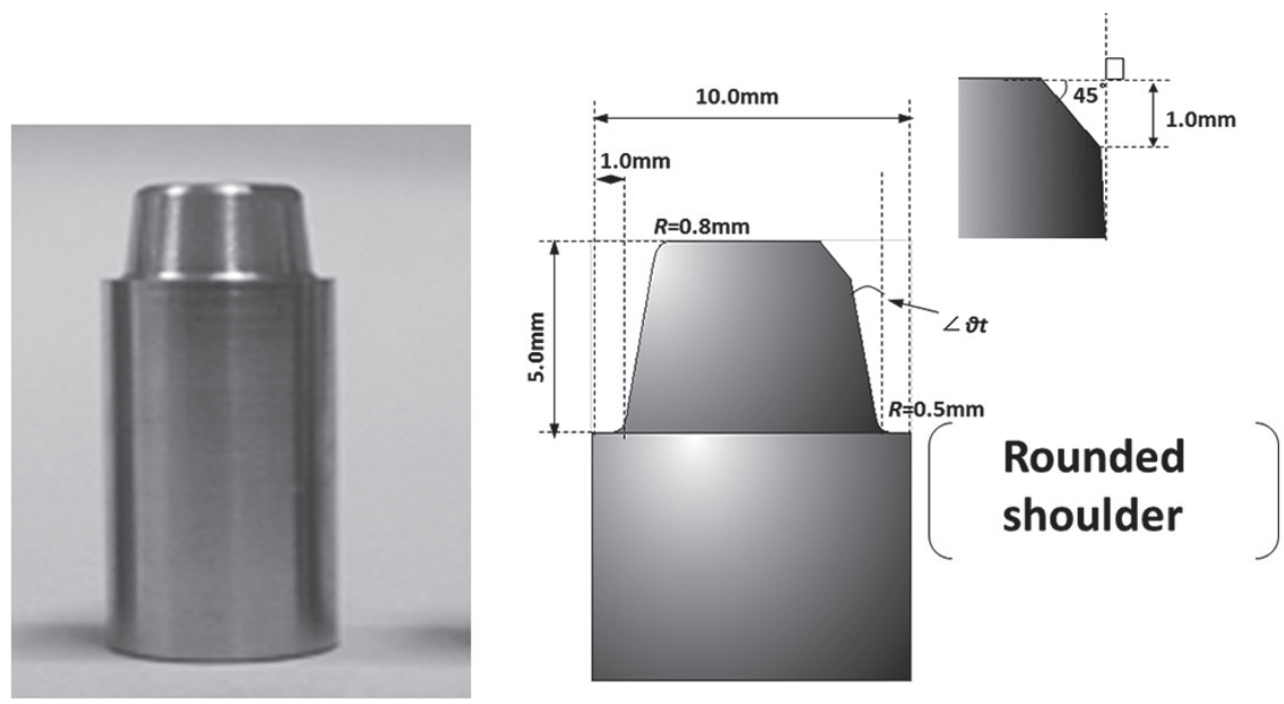

Fig. 1 Metal molds of molar-area abutment tooth morphology and model.
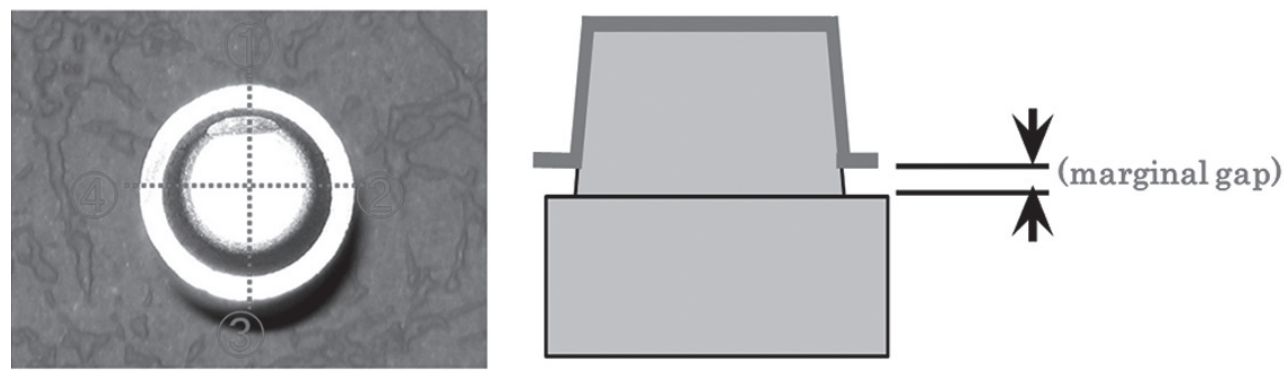

Fig. 2 Measurement position. 
(DupliCone, Shofu, Kyoto, Japan).

The coping was repositioned on the working model after both the primary and secondary firings, and the distance between the working model margin and the margin of the coping was measured at four points (1-4 in Fig. 2) using a universal tool microscope (Topcon TUN200, Topcon, Tokyo, Japan). The mean of the measured values for the four spots was taken as the marginal gap. Ten samples were prepared for each of the experimental conditions.

Test 2 examined the porcelain build-up on the all-ceramic crown copings following the primary and secondary firings. The porcelain build-up process was conducted in accordance with the manufacturer's instructions, using BASE DENTINE (VITA Hakusui Trading), TRANSPA DENTINE (VITA Hakusui Trading), and ENAMEL (VITA Hakusui Trading) as powders, and MODELLING LIQUID (VITA Hakusui Trading) as a solution. Ten samples were prepared for each of the firing conditions. The inner and outer surfaces of the crowns after porcelain firing were macroscopically observed.

Test 3 investigated the fit performance of the crowns formed via porcelain build-up on the copings after primary firing. When porcelain was built up on the copings that had undergone secondary firing using the process described in test 2, cracking occurred throughout the porcelain. Therefore, we investigated the performance of copings that did not undergo secondary firing. A working model produced by a method similar to test 1 was used to investigate the marginal gaps of the copings after primary firing, and the changes in the fits of the crowns obtained following porcelain build-up were examined. Two conditions were examined, i.e., three- or four-layer coping thickness during primary firing. Ten samples were prepared for each of the conditions.

Test 4 investigated the crown bending strength following porcelain build-up and firing. A three-point bending strength test was performed in order to measure the strengths of the crowns obtained through porcelain build-up onto copings following primary firing. The experimental materials and methods are described below, along with the sample production method.

1) A planar working model was prepared using super-hard gypsum (New Fujirock IMP, GC) after an impression was taken of a two-ply prepared sample using a silicone impression material for multiple molds (DupliCone, Shofu).

2) The working model was trimmed to a size of $40 \times 30 \mathrm{~mm}^{2}$. Porcelain was built up and fired on the copings produced in the coping production steps 1-7 above. The samples had either three or four coping layers.

3) The planar samples of the porcelain fired in step 2 were curved slightly to the porcelain side as a result of contraction of the porcelain. Therefore, impressions of the fabricated samples were taken using a silicone impression material (Exafine ${ }^{\circledR}$ Putty-type, GC), and super-hard gypsum (New Fujirock IMP, GC) was used to prepare a working model in accordance with the plaster contraction.

4) The curved working models that were prepared in step 3 were used to prepare planar samples, which were obtained via porcelain build-up and firing on the coping in a method similar to step 2. For these samples, the curvature of the working model was corrected by the porcelain contraction, thus producing a planar shape with almost no curvature.

5) Figure 3 shows a planar sample produced in step 4. The Japanese Industrial Standards (JIS) state that the dimensions of a bending test piece should be: width $w=4.0 \pm 0.2 \mathrm{~mm}$; thickness $b=1.2-3.0$ $( \pm 0.2 \mathrm{~mm})$; and chafer $c=0.09-0.15 \mathrm{~mm}$. Further, the specimen must have a length that is at least 2

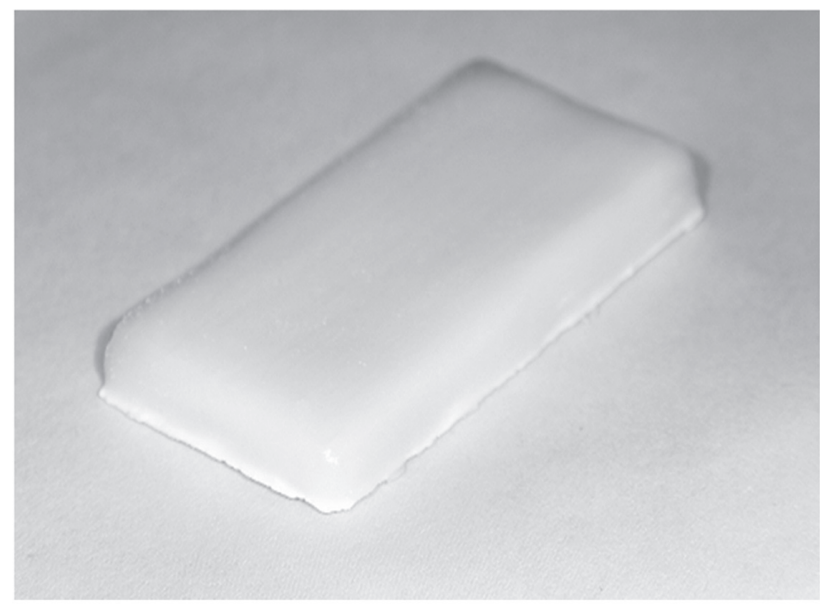

$40 \times 30 \times 4 \mathrm{~mm}$

Fig. 3 Bending test piece planar shape after porcelain firing.

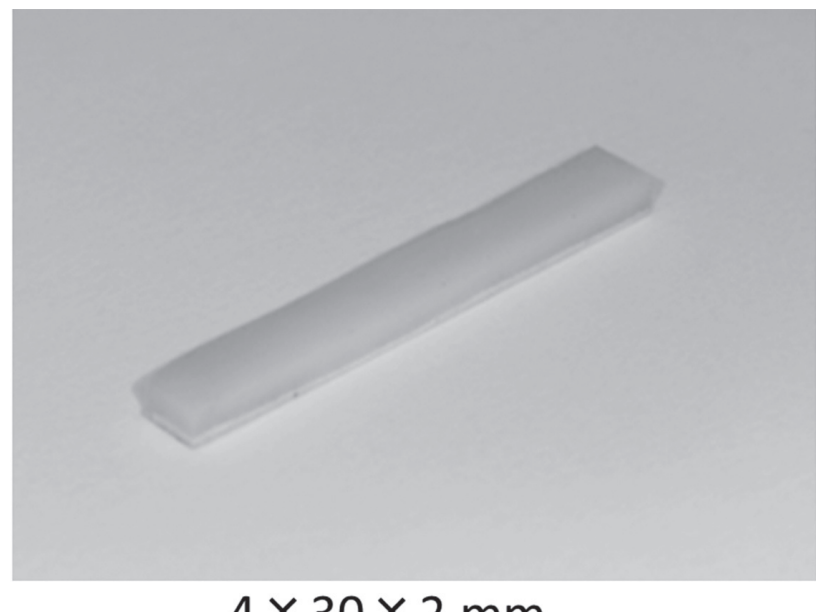

$4 \times 30 \times 2 \mathrm{~mm}$

Fig. 4 Completed test piece for bending test. 
$\mathrm{mm}$ longer than the fulcrum distance $l=12.0-40.0$ $( \pm 0.5)$ of the three-point bending test instrument. Finally, a $b / l$ ratio of 0.1 or lower is required. Therefore, the test pieces were prepared by cutting the samples to a size of $4 \times 30 \times 2 \mathrm{~mm}^{3}$ so as to conform to the JIS standard. Three test pieces were prepared from a single sample (Fig. 4).

6) The test pieces were prepared both with and without luting cement (G-CEM Link Ace, GC), which was pressed against the coping surfaces of the test pieces prepared in step 5 .

Measurements were taken using a tester MODEL-1308 (Aikoh Engineering, Higashiosaka, Japan) onto which a three-point bending test jig was installed. The test piece was placed on the three-point bending test jig and a vertical load was then applied to the center of the test piece. This tester can measure the load required to fracture a test piece to an accuracy of $\pm 0.1 \mathrm{~N}$. The crosshead speed was set to $1 \pm 0.5 \mathrm{~mm} /$ min. The three-point bending strength was determined according to the formula

$$
\sigma=\frac{3 P l}{2 w b^{2}}
$$

Where is the three-point bending strength $(\mathrm{MPa})$ and $P$ is the fracture load $(\mathrm{N})$.

The fracture surfaces of test pieces fractured during the three-point bending strength test were observed with a scanning electron microscope (SEM, S-4000, Hitachi, Tokyo, Japan). Ten samples were prepared for each of the above-described preparation conditions.

\section{RESULTS}

Test 1: Coping fit dependence on heating rate during secondary firing (glass infiltration firing)

Figure 5 shows the marginal gaps of the copings after

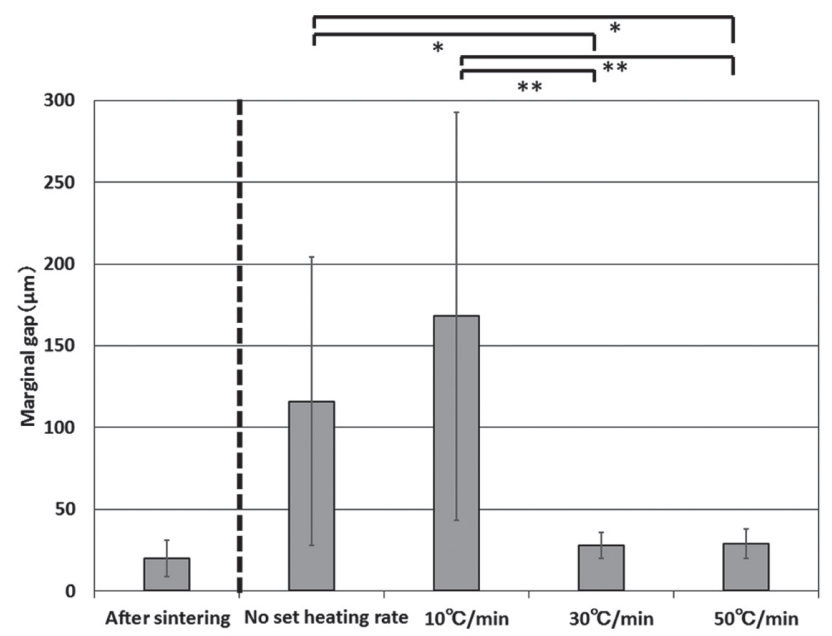

Fig. 5 Marginal gaps for primary and secondary firings. primary and secondary firings. The mean marginal gap of the coping after primary firing was $20 \mu \mathrm{m}$. The marginal gap after secondary firing was smallest for the heating rate of $30^{\circ} \mathrm{C} / \mathrm{min}$, with a mean value of 28 $\mu \mathrm{m}$, while the greatest marginal gap was obtained for a temperature increase of $10^{\circ} \mathrm{C} / \mathrm{min}$, with a mean value of $125 \mu \mathrm{m}$.

The result of a one-way analysis of variance (ANOVA) considering the heating rate for secondary firing indicated that the rate of temperature increase affected the marginal gap significantly, with a hazard ratio of $1 \%$. Therefore, when tested using Fisher's least significant difference method, the 30 and $50^{\circ} \mathrm{C} / \mathrm{min}$ conditions corresponded to a smaller marginal gap than the $10^{\circ} \mathrm{C} / \mathrm{min}$ heating condition, with a $1 \%$ hazard ratio. The samples fired with no set heating rate exhibited a $5 \%$ hazard ratio.

\section{Test 2: Porcelain build-up performance}

Figure 6 shows an all-ceramic crown obtained through the build up and firing of porcelain on a coping that underwent secondary firing. Cracking occurred throughout the porcelain in all ten of the samples produced in this manner. Macroscopic observation from the crown outer surface revealed that cracking occurred throughout the entire coronal portion. No cracking occurred on the inner surface. Figure 7 shows an allceramic crown obtained through the build-up and firing of porcelain onto a coping that underwent primary but not secondary firing. When porcelain was built up onto these coping specimens, all ten samples yielded crackfree crowns.

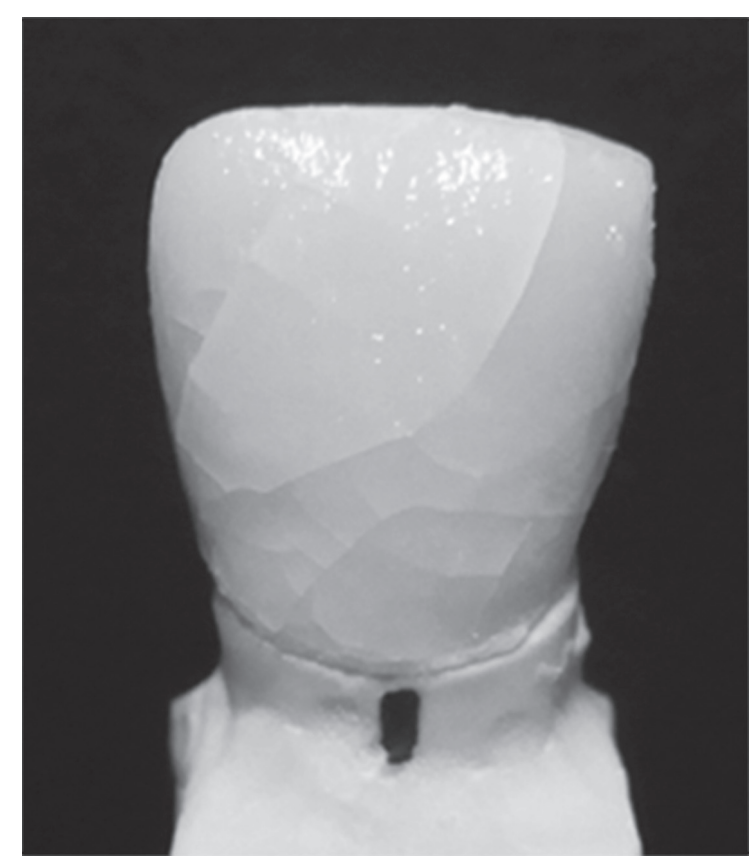

Fig. 6 Crown with cracks. 


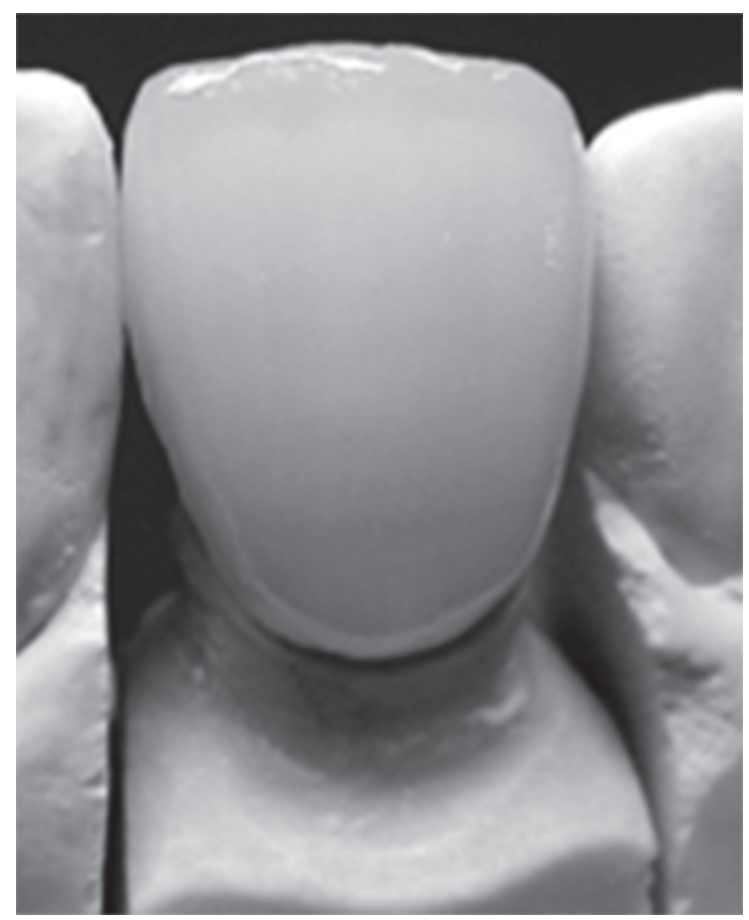

Fig. 7 Crown with no cracks.

Test 3: Fits of crowns obtained via porcelain build-up on a primary-fired coping

Figure 8 shows the marginal gap of a crown after primary firing and porcelain build-up, for three- and four-layer copings. The mean marginal gap of the copings after primary firing was $20 \mu \mathrm{m}$ for both the three- and fourlayer specimens, while the mean values after porcelain firing were 25 and $24 \mu \mathrm{m}$ for the former and latter, respectively. A two-way ANOVA test with the number of layers and porcelain firing as factors indicated that the marginal gap was not significantly affected by the number of layers or by the porcelain firing.

Note that this method further shortened the working time, because no secondary firing was performed. That is, the total time required to complete the coping was $14 \mathrm{~min}$ : Approximately $1 \mathrm{~min}$ for the mixing clay preparation (for the slip), 12 min for the porcelain buildup and drying, and $1 \mathrm{~min}$ for the temporary firing. The time required for the porcelain build-up and firing was approximately $45 \mathrm{~min}$, and the preparation time for allceramic crowns using this method is approximately $1 \mathrm{~h}$.

Test 4: Bending strength after porcelain build-up and firing

Figure 9 illustrates the three-point bending strength measurement result. The mean value for a threelayer coping specimen without the use of cement was 72.0 $\mathrm{MPa}$, while that for a three-layer specimen with cement was $74.3 \mathrm{MPa}$. The mean values for four-layer specimens with and without cement were 79.8 and 73.3 $\mathrm{MPa}$, respectively. The results from a two-way ANOVA

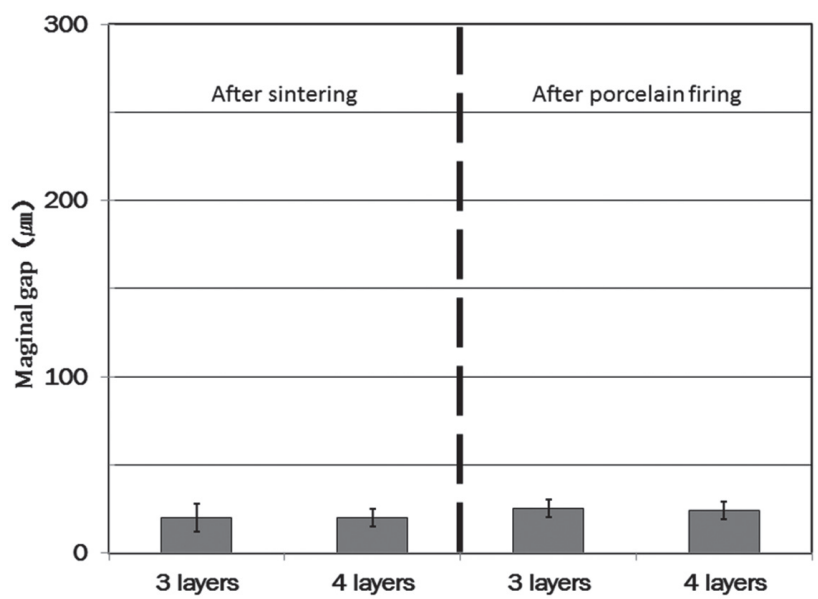

Fig. 8 Marginal gaps after sintering and after porcelain firing.

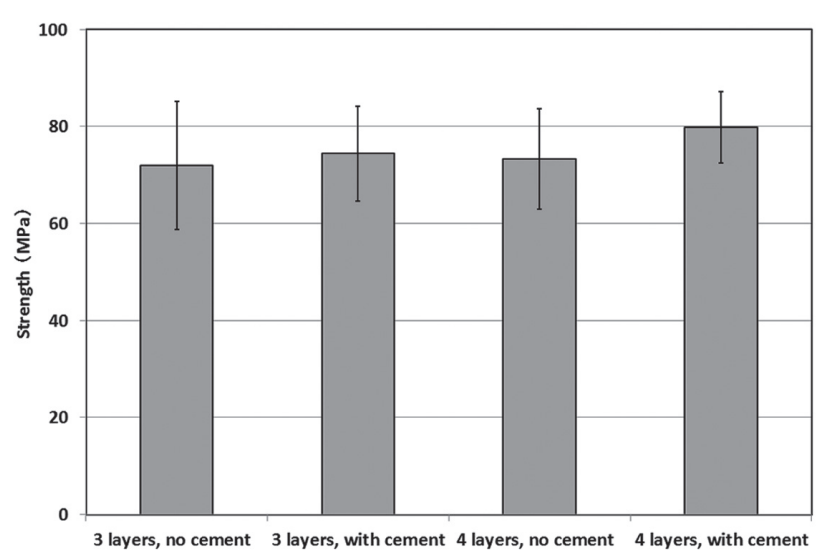

Fig. 9 Strength with and without cement.

considering the number of layers and the presence/ absence of cement indicated that the bending strength was not significantly affected by the number of layers or by the presence/absence of cement.

Figure 10 shows SEM images of the fracture surfaces of the examined specimens. Many irregularities can be observed in the coping portions of the fracture surfaces of the specimens without cement, for both the threeand four-layer specimens. However, fewer irregularities occurred on the coping portions of the specimens for which cement was used.

\section{DISCUSSION}

Test 1

The purpose of glass infiltration is to maintain strength. Previous studies in which glass infiltration was conducted without a determined rate of temperature increase have concluded that the strength is maintained but the fit accuracy is decreased ${ }^{3,4}$. Attempts were therefore made 


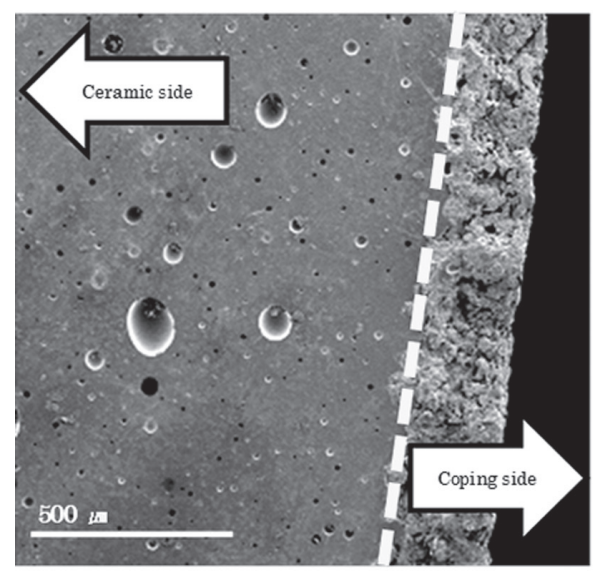

3 layers, no cement

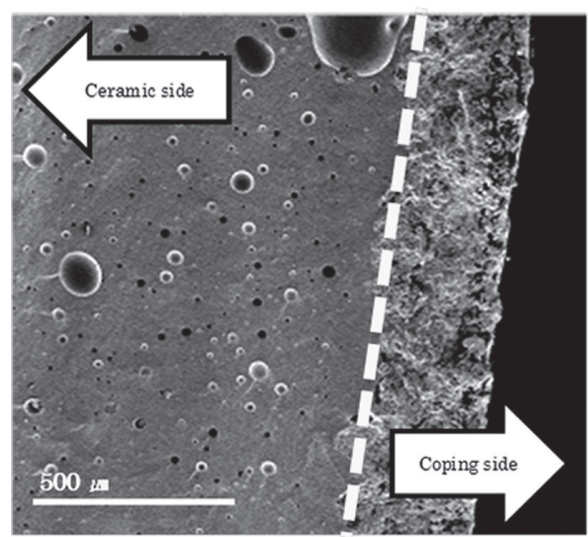

3 layers, with cement

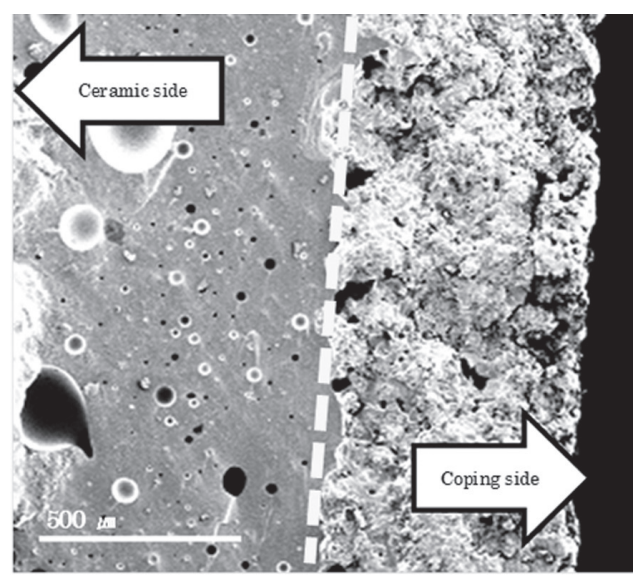

4 layers, no cement

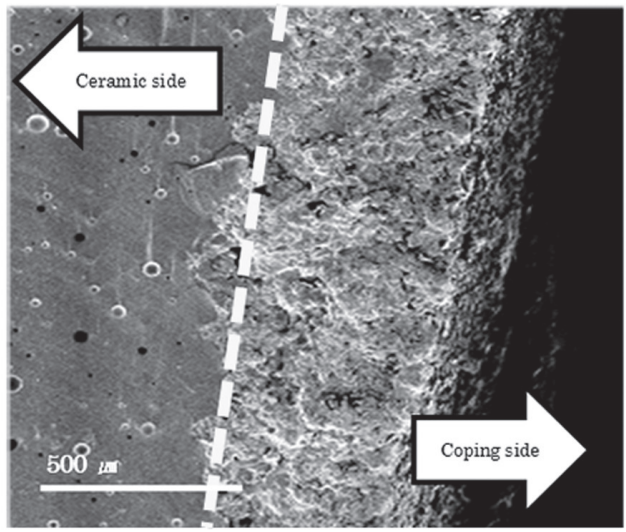

4 layers, with cement

Fig. 10 Fracture surfaces of test pieces after porcelain build-up and firing.

in this study to improve crown fit performance while also maintaining strength, by setting the heating rate. Of the four examined conditions: 1) no set rate of temperature increase; 2) $10^{\circ} \mathrm{C} / \mathrm{min}$; 3) $30^{\circ} \mathrm{C} / \mathrm{min}$; and 4) $50^{\circ} \mathrm{C} / \mathrm{min}$, the optimal fit was obtained for the $50^{\circ} \mathrm{C} / \mathrm{min}$ temperature increase, followed by the $30^{\circ} \mathrm{C} / \mathrm{min}$ condition.

This demonstrates that the heating rate significantly affects the fit. If the heating rate is between 10 and $50^{\circ} \mathrm{C} /$ $\mathrm{min}$, then the fit is enhanced as the rate of temperature increases. Note that some spillover of the infiltration glass at the inner surface of the coping was observed in this study; this is thought to be a major cause of the poor fit obtained for certain conditions.

Figure 11 shows the relationship between time and temperature for each of the examined heating conditions. The heating times to $1,100^{\circ} \mathrm{C}$ are 110,37 , and $22 \mathrm{~min}$ at 10,30 , and $50^{\circ} \mathrm{C} / \mathrm{min}$, respectively; of course, a greater rate of temperature increase corresponds to a shorter heating time, so the infiltration glass is less likely to spill over to the inner surface. The shortest heating time to $1,100^{\circ} \mathrm{C}$ is obtained if no rate of temperature increase is set, at $19 \mathrm{~min}$. However, the specimen fit is worse than for the 30 or $50^{\circ} \mathrm{C} / \mathrm{min}$ heating rates. The times required to attain $1,100^{\circ} \mathrm{C}$ from $824^{\circ} \mathrm{C}$ are approximately 6,10 ,

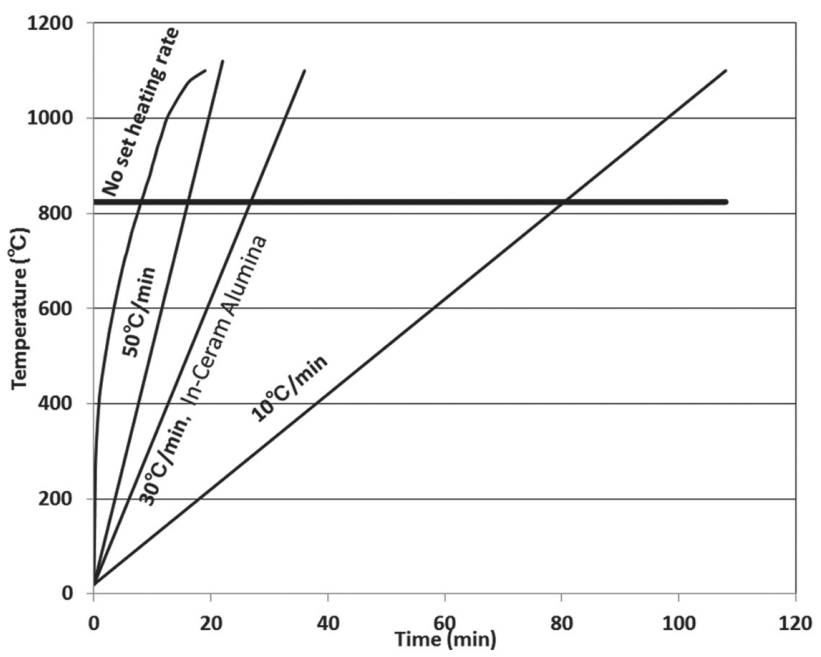

Fig. 11 Heating rate trends for various conditions.

11 , and $27 \mathrm{~min}$ for the $50^{\circ} \mathrm{C} / \mathrm{min}, 30^{\circ} \mathrm{C} / \mathrm{min}$, no setting, and $10^{\circ} \mathrm{C} / \mathrm{min}$ heating conditions, respectively; this time order corresponds to the order of fit performance 
well. That is, the fit performance does not appear to be affected by the heating time to $1,100^{\circ} \mathrm{C}$, but rather by the time required to attain 1,100 from $824^{\circ} \mathrm{C}$, which is the softening temperature of the glass.

As regards holding time variations, the fit was poor only in the case where no setting was imposed, despite that fact that the effects of 30, 40, 50, and 60 min holding times were examined. The 60 -min holding time was imposed for the 50,30 , and $10^{\circ} \mathrm{C} / \mathrm{min}$ heating rates, and the fits were found to be favorable at 50 and $30^{\circ} \mathrm{C} / \mathrm{min}$, but poor at $10^{\circ} \mathrm{C} / \mathrm{min}$. In other words, the holding time is not thought to affect the crown fit significantly.

The In-Ceram alumina technique was used to employ the alumina coping. This involves the use of multiple dies on which the coping is produced (alumina coping with glass infiltration), followed by porcelain build-up and firing. The secondary firing stage involves heating from 200 to $1,120^{\circ} \mathrm{C}$ within a heating time of $30 \mathrm{~min}$ at a rate of $30^{\circ} \mathrm{C} / \mathrm{min}$, with a 2 -h holding time. With In-Ceram Alumina, the alumina is sintered and the coping is therefore dense, thus, the glass infiltration stage is thought to require a long period of time. The fit discrepancy is $22-77 \mu^{8-11)}$, and the strength is 600-1,060 $\mathrm{MPa}^{12,13)}$. In this study, the fit performance was essentially identical for both the 50 and $30^{\circ} \mathrm{C} / \mathrm{min}$ heating conditions using the proposed method.

\section{Test 2}

Glass infiltration firing was performed with reference to the method using the In-Ceram Alumina. In this approach, glass infiltration is considered to dramatically reduce the numerous bubbles and defects that occur in alumina copings.

When this method was applied in this study, cracking occurred throughout the built-up porcelain. This is thought to be because the porcelain firing temperature is approximately $915^{\circ} \mathrm{C}$, whereas the glass melting temperature is $824^{\circ} \mathrm{C}$, therefore, a temperature difference of approximately $100^{\circ} \mathrm{C}$ occurs. During cooling, the porcelain solidifies first, followed by the glass. The solidification contraction of the glass that occurs during this time is believed to exert stress on the porcelain, generating cracks. The cracking is also believed to be caused by the partial mixing that occurs at the porcelain-glass boundary, or as a result of eutectic or other reactions.

With In-Ceram, cracking was not observed in the completed crowns even if the porcelain was built up and fired after the secondary firing. This is believed to be because the alumina coping was sintered during the primary firing stage, so only a limited amount of glass penetration occurred; hence, there was a smaller contact surface area between the porcelain and glass. It is believed that cracking did not occur because there was no low-melting-point glass present in the copings that were not subjected to glass infiltration.

\section{Test 3}

The glass infiltration process is used during coping fabrication to suppress the contraction of the all- ceramic crown ${ }^{14)}$. However, for the cases in which glass infiltration was not performed in the present study, the fit was extremely favorable for both the coping and the all-ceramic crown with the built-up porcelain, and very little contraction is thought to have occurred. When the porcelain was previously built up onto a sintered alumina coping, the coping itself had significantly larger stability, hence, it was possible for the contraction to be suppressed. However, unsintered alumina coping is very brittle, and it is deformed if porcelain firing is performed $^{14)}$.

The strengths of the copings fabricated in the present study were very low. However, almost no decrease in fit due to porcelain firing was observed. As such, it appears that only the coping strength necessarily affects contraction during porcelain firing.

The acceptable range of fit discrepancy at present is $30-60 \mu \mathrm{m}$ for all-cast crowns ${ }^{15-18)}$. At $120 \mu \mathrm{m}$ or lower, long-term progression is reportedly also favorable ${ }^{19)}$. Wilson has reported that a cemented region of approximately $30 \mu \mathrm{m}$ is necessary for accurate fitting of cast crowns, considering the size of the particles in the luting material ${ }^{20)}$. Via CAD/CAM, a fit discrepancy of 22$49.8 \mu \mathrm{m}$ has been reported for feasible manufacturing ${ }^{21-24)}$. In the present study, the mean values after porcelain firing were 25 and $24 \mu \mathrm{m}$ for the three- and four-layer specimens, respectively, which is regarded as being sufficient for clinical applications.

\section{Test 4}

Irrespective of whether or not a luting material was used, the higher bending strength values were obtained for four-layer rather than three-layer copings. For both the three- and four-layer cases, the presence of cement corresponded to slightly enhanced bending strength. This is thought to be because the luting material entered the large number of minute voids present in the coping.

When the fracture surfaces were observed via SEM, almost no irregularities were apparent on the fracture surfaces of test pieces that contained cement, with the cement being observed to have penetrated the coping. This is believed to be the source of the increased strength. However, only a slight difference in strength was observed, and the overall strength of the crown is thought to have been largely unaffected.

The overall thickness of the fabricated crowns was $2 \mathrm{~mm}$, whereas the coping thickness was approximately $0.5 \mathrm{~mm}$, thus, the coping strength can be said to have had little impact on the overall crown strength. This is thought to be why the number of layers or the presence/ absence of cement corresponded to a slight difference in bending strength. This difference was not major, and was not statistically significant ${ }^{25)}$.

The JIS quotes a bending strength of $50 \mathrm{MPa}$ or higher as sufficient for use with anterior crowns, inlays, and laminate veneers. Accordingly, the all-ceramic crowns produced via this method are considered to be clinically applicable to anterior crowns. 


\section{CONCLUSION}

The fit was best when secondary firing was performed at $50^{\circ} \mathrm{C} / \mathrm{min}$ and worst for a heating rate of $10^{\circ} \mathrm{C} / \mathrm{min}$. Cracking occurred throughout the crown when porcelain was built up and fired on a coping that had undergone secondary firing. However, a crack-free crown was successfully produced if porcelain was built up and fired on a coping without secondary firing. The mean marginal gap was $20 \mu \mathrm{m}$ for copings with both three and four layers during the porcelain build-up. The mean strength was $72 \mathrm{MPa}$ for the three-layer case without cement, and $74.3 \mathrm{MPa}$ for that with cement. The mean strength was $73.3 \mathrm{MPa}$ for the four-layer specimen without cement, and $79.8 \mathrm{MPa}$ for that with cement. The production time for all-ceramic crowns using this method was approximately $1 \mathrm{~h}$.

These findings establish that this method can produce all-ceramic crowns that are suitable for application as anterior crowns. Further, this technique allows manufacture within a short period of time of approximately $1 \mathrm{~h}$.

\section{ACKNOWLEDGMENTS}

We wish to express our deep gratitude to Taisei Dental Mfg for their collaboration, advice, and for the materials they provided for the present study. The present study was conducted with the support of Osaka Dental University Research Funds.

A summary of this study was presented at the 65th (Autumn) academic meeting of the Japanese Society for Dental Materials and Devices (12 April 2015, Sendai City).

\section{REFERENCES}

1) Chong BJ, Thangavel AK, Rolton SB, Guazzato M, Klineberg IJ. Clinical and laboratory surface finishing procedures for zirconia on opposing human enamel wear: A laboratory study. J Mech Behav Biomed Mater 2015; 50: 93-103.

2) Preis V, Behr M, Kolbeck C, Hahnel S, Handel G, Rosentritt $\mathrm{M}$. Wear performance of substructure ceramics and veneering porcelains. Dent Mater 2011; 27: 796-804.

3) Masuda T, Kakimoto K, Kitao N, Takahashi K, Komasa Y. Fabrication of all-ceramic crowns by a new method based on improvements in the conformity drying method. Shika Igaku 2015; 78: 7-12.

4) Inoue T, Kakimoto K, Komasa Y. Improvement in coping strength of all-ceramic crowns by a new method. Shika Igaku 2010; 73: 77-85.

5) Koishi A, Kakimoto K, Komasa Y. Fabrication of an allceramic crown by a new method: Second report. Shika Igaku 2007; 70: 91-103.

6) Kakimoto K, Koishi A, Okazaki J, Yamamoto C, Komasa Y. All-ceramic crown by new method: The first report. J Jpn Prosthodont Soc 2007; 51: 58-66.
7) Friedlander LD, Munoz CA, Goodacre CJ, Doyle MG, Moore BK. The effect of tooth preparation design on the breaking strength of Dicor crowns: Part 1. Int J Prosthodont 1990; 3: 159-168.

8) Pelekanos S, Koumanou M, Koutayas SO, Zinelis, S, Eliades G. Micro-CT evaluation of the marginal fit of different InCeram alumina copings. Eur J Esthet Dent 2009; 4: 278-292.

9) Shearer B, Gough MB, Setchell DJ. Influence of margin configuration and porcelain addition on the fit of Inceram crowns. Biomaterials 1996; 17: 1891-1895.

10) Castellani D, Baccetti T, Clauser C, Bernardini UD. Thermal distortion of different materials in crown construction. $\mathrm{J}$ Prosthet Dent 1994; 72: 360-366.

11) Kappert HF, Altvater A. Field study on the accuracy of fit and marginal seal of In-ceram crown and bridges. Dtsch Zahnarzt 1991; 46: 151-153.

12) Yoshinari M, Derand T. Fracture strength of all-ceramic crowns. Int J Prosthodont 1994; 7: 329-338.

13) Guazzato M, Albakry M, Swain MV, Ironside, J. Mechanical properties of in-ceram alumina and in-ceram-zirconia. Int $\mathrm{J}$ Prosthodont 2002; 15: 339-348.

14) Magne P, Belser U. Esthetic improvements and in vitro testing of In-Ceram Alumina and Spinell ceramic. Int J Prosthodont 1997; 10: 459-466.

15) Shinya A, Ohsawa J, Kobayashi N, Warita K, Furuya R, Kawawa T. A comparative study on the marginal discrepancies of full cast crowns. Showa Univ Dent Soc 1995; 15: 311-314.

16) Boeckler, AF, Stadler, A, Setz, JM. The significance of marginal gap and overextension measurement in the evaluation of the fit of complete crowns. J Contemp Dent Pract 2005; 6: 26-37.

17) Konstantoulakis E, Nakajima H, Woody RD, Miller AW. Marginal fit and surface roughness of crowns made with an accelerated casting technique. J Prosthet Dent 1998; 80: 337345 .

18) Christensen GJ. Marginal fit of gold inlay castings. J Prosthet Dent 1966; 16: 297-305.

19) Mclean JW, von Fraunhofer JA. The estimation of cement thickness by an in vivo technique. Br Dent J 1971; 131: 107111.

20) Wilson PR. Effect of increasing cement space on cementation of artificial crowns. J Prosthet Dent 1994; 71: 560-564.

21) Uno M, Nonogaki R, Yokoyama Y, Yamamura Y, Ishigami H, Kurachi M. Effect of heating CAD/CAM-fabricated ceramic crowns on marginal fit accuracy. Prosthodont Res Pract 2007; 6: 81-86.

22) Vojdani M, Safari A, Mohaghegh M, Pardis S, Mahdavi F. The effect of porcelain firing and type of finish line on the marginal fit of zirconia copings. J Dent Shiraz Univ Med Sci 2015; 16: 113-120.

23) Farid F, Hajimiragha, H, Jelodar, R, Mostafavi, AS, Nokhbatolfoghahaie H. In vitro evaluation of the effect of core thickness and fabrication stages on the marginal accuracy of an all-ceramic system. J Dent (Tehran) 2012; 3: 188-194.

24) Euán R, Figueras-Álvarez O, Cabratosa-Termes J, OliverParra R. Marginal adaptation of zirconium dioxide copings: Influence of the CAD/CAM system and the finish line design. J Prosthet Dent 2014: 112: 155-162.

25) Nakamura T, Sugano T, Usami H, Wakabayashi K, Ohnishi H, Sekino T, Yatani H. Shear bond strength of veneering porcelain to porous zirconia. Dent Mater J 2014; 33: 220225 . 